\title{
Os museus no futuro do Brasil ${ }^{1}$
}

\section{JACQUES MARCOVITCH ${ }^{I}$}

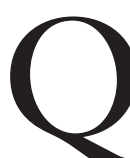

UANDO, na Semana dos Museus do Rio Grande do Sul, realizada em 2000, o professor Ulpiano Toledo Bezerra de Menezes formulou a pergunta "O museu tem futuro?", ele afirmou, de um lado, a sua crença na "necessidade de um espaço estável, de acesso social, que permita exercer ou aprofundar a consciência da realidade material, assim como de sua historicidade". Mas, por outro lado, para que tal necessidade se imponha, o professor Ulpiano observou que o museu deve superar quatro riscos.

O primeiro risco é o de se esquecer de sua especificidade que se define na exploração do universo material. O segundo risco é o de sucumbir às seduções do espetáculo, da sensação redutora, da pura vivência - ainda mais que a tecnologia fornece recursos cada vez mais eficazes para tanto. O terceiro, apresentado como compromisso, seria assumir uma postura crítica, transformando-se num espaço mais de indagações e inquietações, que de respostas, confirmações e acomodação. Finalmente, para respeitar suas responsabilidades sociais, precisa o museu vencer as tentações do mercado para mitigar o quarto risco. (Meneses, 2000)

Submeto à análise desta assembleia um quinto risco, o da falta de boa governança nos museus, a ser superada para que estas instituições estejam presentes e ativas no futuro do Brasil.

A maioria dos grandes museus do mundo pertence aos governos e a sua gestão é confiada a servidores públicos. Do trabalho dessas pessoas venho falar aqui, tendo como foco a excelência e também o oposto desta virtude. Não sou museólogo, e sim estudioso das organizações humanas e da sua governança, o que me leva a discorrer sobre esta componente das humanidades, frequentemente subestimada na atividade cultural.

Em sentido lato e abrangente a administração pública é um conjunto de ações voltadas aos serviços prestados à coletividade pelas instituições que compõem o Estado. A governança dos museus, inserida nesta indicação conceitual, distingue-se pelo fato de ofertar aos cidadãos bens imateriais como a satisfação estética, o conhecimento da história humana e outros saberes transformadores.

Tendo convivido mais proximamente com diretores de museus, farei um pouco adiante, nesta abordagem, algumas considerações sobre as suas bem-sucedidas gestões. Também me ocuparei mais detidamente de algumas práticas que inibem as boas ações administrativas. Inicialmente, compartilharei com os presentes um episódio na cena cultural europeia que chama a atenção. Estou me referindo aos acontecimentos relacionados com os museus públicos italianos e dos quais tentarei resumir os aspectos factuais. 


\section{A “transformação" italiana}

Tudo começou com um anúncio recrutando estrangeiros para dirigir os museus do Estado. Os convites foram publicados pelo Ministério da Cultura em revistas e jornais do exterior. Pela primeira vez na história, tradicionais museus da Itália buscavam, fora do país, e sem exigir fluência no idioma local, especialistas com experiência de gestão que pudessem comandar uma profunda reestruturação em suas estruturas. São novos diretores escolhidos por meio de seleção pública, submissão de projetos plurianuais e entrevistados por um painel de especialistas.

As transformações previstas para as instituições de Roma, Firenze, Milão e outras cidades espelham-se na experiência gestora de estabelecimentos modelares da França e da Espanha, como o Louvre e o Prado. O governo italiano já decidiu que os administradores empossados terão mais influência sobre os orçamentos e maior latitude para arrecadar recursos extraorçamentários que complementem o financiamento estatal.

O ministro da Cultura, escritor Dario Franceschini, admite que os museus públicos daquele país demandam maior dinamismo, interação multimídia e outros melhoramentos. Além disso, a comunidade cultural exige que os novos dirigentes tenham um controle crucial da parte técnica, administrativa, jurídica e financeira dos estabelecimentos.

Sete especialistas, sendo três alemães, dois austríacos, um inglês e um francês já foram contratados. No total, vinte museus já têm novos diretores. A transformação mais comentada foi na Galeria Uffici, de Firenze, que será dirigida pelo historiador alemão Eike Schmidt, de 47 anos. Outro grande patrimônio cultural de Firenze, a Galeria da Academia, onde está o Davi de Michelangelo, também passou às mãos de uma especialista alemã, Cecília Holberg, de 48 anos, historiadora de arte e gerente cultural.

Como percebem, está acontecendo uma grande transformação na Itália, que merece ser acompanhada. Conhecer os resultados de uma iniciativa aparentemente corajosa e saudável é um caminho para identificar aspectos que se coadunem com a realidade existente no Brasil. Não se recomenda copiá-las, e muito menos comparar a situação da Itália com a nossa. É aconselhável acompanhar o processo até mesmo para evitar uma automática e imprópria transposição de métodos.

\section{Um novo perfil}

A busca de novos dirigentes de Museus na Itália, com um perfil predeterminado, nos leva a refletir sobre os elementos que sustentam a formação dos dirigentes de museus no Brasil. Em muitos casos é necessário ajustar os perfis e adotar modelos curriculares mais compatíveis com as exigências da gestão contemporânea. Aptidão para o planejamento de longo prazo, gestão de projetos, administração de orçamentos e estruturação de prioridades constituem iguais qualificações na escolha e comando das equipes ao seu redor; e a consciência de 
que, mesmo não exercendo mandato diretivo, um aspirante a tal encargo deve ter competências que o credenciem ao exercício da liderança pretendida.

Habilitado academicamente em arte ou ciência que corresponda às atividades-fim do museu, o dirigente em potencial precisa capacitar-se em outro domínio, o da gestão, para conduzir uma atividade-meio que é essencial ao bom desempenho da instituição.

É lógico que não se podem encontrar na mesma pessoa todas as características desejáveis, mas é necessário, pelo menos, que a pessoa escolhida tenha uma noção exata do conjunto de profissionais que vai dirigir. Deve encarnar, perante a sociedade, valores compatíveis com a representação cultural que está assumindo. Espera-se ainda - e isso não é uma questão acessória, mas um traço fundamental do seu perfil - que tenha a capacidade de articular uma visão de futuro. O gestor, neste caso, precisa ter em mente, a partir do que pode apreender com a coletividade onde trabalha, uma proposta estratégica e não somente o aspecto rotineiro do seu cargo.

Alguns intelectuais têm maior vocação para empreender iniciativas inovadoras, outros, menos. Há os que consideram essa tarefa aborrecida, outros, "um mal desnecessário" e privilegiam aspectos mais relacionados à pesquisa. As tarefas administrativas, neste caso, deveriam ser atribuídas a uma equipe de alto nível, mas dela deve necessariamente participar o gestor principal.

O condutor de um projeto cultural, qualquer que seja, tem a missão de torná-lo estimado pela sociedade. Um diretor de Museu, além disso, também deve mostrar-se capaz de obter recursos externos e ampliar as fronteiras de sua instituição. É desejável que aprimore seus dons de comunicador, procure selecionar as informações relevantes sobre o museu e identificar corretamente o que deve ser comunicado. No caso de um museu de arte, nenhum catálogo, por mais convincente que seja, substitui a palavra bem informada e calorosa de um diretor convicto de sua missão.

\section{Um novo sistema organizacional}

Quando Paolo Baratta, presidente da Bienal de Veneza desde 2008, fala em "regras paralisantes e sistemas esclerosados" nos museus italianos, para justificar o recrutamento internacional de diretores, logo nos vem à mente uma prática existente na governança de outros museus estatais.

Cabe dizer que também no campo da cultura o melhor parâmetro no dimensionamento das ações administrativas é a compreensão do sistema organizacional a ser dinamizado. Há quatro vetores a considerar: insumos, processos, resultados e impactos.

Como insumos, além da legislação externa que alimenta e rege as ações de museus, estão os recursos orçamentários ou extraorçamentários. A vertente dos processos abrange o planejamento, a execução e a avaliação dos recursos humanos/financeiros. 
Como resultados são compreendidos a eficácia na gestão dos recursos para colecionar, conservar, estudar e expor para a difusão do conhecimento. Quanto ao eixo dos impactos, estão o desempenho das equipes envolvidas e a imagem de excelência projetada pela qualidade dos seus acervos e exposições.

\section{Fatores paralisantes}

O termo "burocracia" é usado aqui em sua acepção corrente, embora também guarde afinidades com o conceito de Max Weber, segundo o qual "todo o poder se manifesta e funciona como administração" (Bobbio, 1998). Fiquemos, porém, no significado que se cristalizou na linguagem comum e, criticamente, aponta para o excesso de regras nocivas à consumação de boas ideias nas organizações estatais. A demasia regulatória transformou-se numa espécie de ritualismo de Estado, sobreposto ao interesse coletivo.

Em toda a América Latina e no Brasil, é tão pernicioso e tão grande o poder de manobra da burocracia que, ao recomendar prioridades para a ação pública, não se pode omitir a urgente remoção dos obstáculos ao seu fluxo de urgência. Numa hora em que a nação debate mudanças estruturais necessárias ao seu ingresso definitivo na modernidade, convém lembrar a importância de uma reestruturação gerencial que flexibilize a gestão pública, reduza seus níveis hierárquicos e, por via de consequência, amplie a autonomia dos diretores e dos gerentes, que devem ser os técnicos mais qualificados e aptos a tornar o Estado mais eficaz.

Há, dentro das instituições governamentais, e por extensão nos grandes museus do Estado, um entrechoque da cultura de resultados e da cultura de processos. Na cultura de processos, que é dominante, cada problema, iniciativa ou projeto constitui um processo em papel, repleto de pareceres e carimbos, que passa a ser o núcleo dinâmico. Isto sucede na montagem dos mecanismos para a aplicação de uma decisão. Todos os aspectos envolvidos seguem o passo rigoroso do tempo. Em outras palavras, as questões aparecem e evoluem por meio de um protocolo que é dominado pelo tempo, cada etapa incorporando inúmeras análises e apreciações, até a solução, ou a não solução, do problema.

A cultura de resultados focada na qualidade dos serviços, ainda embrionária, implica uma visão mais realista, que tem como referencial a decisão tomada. Nela, sem prejuízo de documentos formais que circulem entre as diversas áreas, a instituição prioriza o resultado a ser obtido. $\mathrm{Na}$ cultura de resultados se valoriza, no início de cada ano, as metas alcançadas no ano anterior, com vistas ao planejamento do exercício vindouro. Nela predominam os objetivos sociais previstos, enquanto, na cultura de processos, apenas o poder é fator determinante. Se conseguirmos inverter esses movimentos, poderemos evoluir para um ambiente mais favorável à geração de proveitos para a sociedade.

Não queremos que as normas e as regras sejam esquecidas. Elas são úteis para a convivência dentro de um coletivo e entre a direção do museu e sua autoridade de tutela. Mas o gestor deve lembrar continuamente que precisam 
ser interpretadas à luz do presente, do passado e do futuro. Em cada momento histórico é necessário adequar decisões ao contexto.

Existe uma contradição que provavelmente os teóricos do Direito poderiam definir melhor: as normas resultam de um determinado quadro conjuntural. São aprovadas num determinado dia e, no dia seguinte, a realidade pode ser outra. Teoricamente, deveriam perder a vigência. Não havendo uma contínua releitura jurídica do que está aprovado, cria-se uma espécie de fundamentalismo burocrático.

O servidor público, aplicando o ritualismo normativo, é credor de uma contrapartida quando age com espírito arejado e inovador. O desempenho profissional das bases do funcionalismo deve ser reconhecido, e seus integrantes formados na direção das melhores práticas. O modelo usualmente julgado como "weberiano" superestima, como foi dito, o controle dos regulamentos, em prejuízo do monitoramento de resultados e seus impactos de médio e longo prazos.

Um novo modelo de gestão inibiria os feudos de mando nas entranhas do Estado e, por via de consequência, na estrutura dos museus e demais centros de cultura? Será este um instrumento eficaz no combate à inércia e a prepotência das chamadas "pequenas autoridades" que alimentam a cultura de processos.

Impõe-se, dentro do setor público, o levantamento de âncoras na estrutura inferior do aparelho cultural do Estado, a fim de que se mova com mais presteza no atendimento às demandas. Enquanto no setor privado a inovação diz respeito fundamentalmente ao avanço tecnológico, no setor estatal ela se evidencia quando relacionada ao desempenho de indivíduos e respectivas mudanças de atitude no trabalho.

Entraves, gargalos, carimbos, vistos e outros artifícios que retardam o andamento das boas ações devem ser questionados e reduzidos ao mínimo. Salvo impedimento legal. Até que a lei, quando assim exigir o interesse geral, seja revogada.

\section{Os museus da USP}

A gestão de um acervo e as atividades de curadoria exigem domínio de habilitações que são requisitos básicos. Agregue-se a estes o complemento subjetivo da sensibilidade para a gestão cultural em todas as suas dimensões. Para ilustrar este ponto, façamos um rápido balanço qualitativo dos museus da Universidade de São Paulo para refletirmos sobre o trabalho dos seus dirigentes.

Os museus da USP constituem um marco em nosso universo cultural. O Museu de Arqueologia e Etnologia, cada vez mais inovador em suas linhas de pesquisa, abriga mais de 900 mil itens de acervo, originários de todo o planeta; o Museu de Arte Contemporânea, o mais importante de América Latina, reúne mais de cinco mil obras e se empenha frequentemente em deslocar parte do seu precioso acervo para exposições periódicas em locais de maior acesso; o Museu Paulista, que enfrenta no momento graves problemas de infraestrutura, retrata a história do Brasil em mais de cem mil peças, incluindo objetos e fotografias; e o 
sempre empreendedor Museu de Zoologia, o maior acervo zoológico do nosso continente, com mais de cinco milhões de exemplares e uma biblioteca científica de mais de 72 mil livros.

Este imenso patrimônio nacional pode oferecer importantes subsídios para novas políticas relativas ao acervo museológico. A Universidade formula, mas também deve ouvir sugestões dos especialistas externos para aperfeiçoar as suas práticas e suas linhas de pesquisa. A USP é hoje - e será cada vez mais no futuro - uma instituição conectada com o universo externo e cada vez mais aberta às contribuições da sociedade.

Um ato irrefletido na gestão da USP ocasionou verdadeira sangria de reservas acumuladas em décadas de sensatez e prudência. $\mathrm{O}$ atual reitor foi obrigado a fazer um ajuste rigoroso, limitando severamente os gastos em todas as áreas. Tais medidas buscam preservar a resiliência financeira da Universidade. Apesar do desgoverno ocorrido em 2012 e 2013, soube-se depois manter a qualidade acadêmica. Permanece, entretanto, um desafio de gerenciamento que talvez seja o mais dramático em toda a história da instituição: a queda vertical na arrecadação do ICMS, da qual depende toda receita da USP. Impõe-se, mais do que nunca, uma gestão austera e eficiente do orçamento.

Os dirigentes dos museus universitários, com os quais convivi profissionalmente mais de perto, são profissionais exemplares, na medida em que se devotam obstinadamente a servir ao Estado, e não a se servir dele. A esses dedicados colegas, que reverencio na figura ímpar do saudoso José Sebastião Witter, aplicaria as palavras de Machado de Assis quando se referiu a devotados homens públicos de seu tempo: "Achava-lhes uma feição particular, metade militante, metade triunfante. Um pouco de pessoa, outro pouco de instituição" (Assis, 1994). Sim, os meus amigos e amigas à frente dos museus uspianos têm a virtude especial de doarem suas vidas ao ofício que escolheram, a ponto de tratar as instituições que dirigem como partes de si mesmos e a elas consagrarem quase todas as horas de seus pensamentos.

\section{Uma proposta}

Autoridades culturais muito ganhariam com um olhar para a inserção dos museus e sua governança em outras culturas como a Itália para a preparação de circunstanciado relatório sobre os problemas que determinaram a impactante reforma administrativa em marcha, bem como as metas fixadas pelas instâncias diretivas da cultura. Creio que o governo central do Brasil, atendendo a uma demanda de todos os museus estatais, poderia tomar esta iniciativa. Tal providência, dentre outras, emergiria de um seminário nacional de governança museológica. Eis a proposta que deixo aqui consignada, naturalmente sujeita ao crivo profissional de quem, dentro da Universidade, governa os seus museus, e governa com grande competência.

Esta iniciativa pode integrar, entre outros itens, um sempre adiado projeto nacional de cultura. Poderá instigar talvez a difusão de uma visão estratégica. Os 
museus do Brasil, no futuro, serão o que fizermos deles no presente. Além de preservar a memória do tempo que foi, cabe-lhes identificar, na cena contemporânea, as hipóteses de perenidade. Somente o olhar atento dos museólogos é capaz de capturar, na arte e na vida, o que representará o nosso tempo durante as décadas e os séculos vindouros.

\section{Palavras finais}

É possível que se aponte nestas considerações um viés “produtivista” e empresarial. Deixem-me ponderar que a linguagem da eficiência e da eficácia reflete os interesses da sociedade representada pelos cidadãos contribuintes, principalmente aqueles mais necessitados de bons serviços públicos. Acrescente-se que o objeto de reparos, nesta palestra, a má gestão, também se encontra nas empresas ineficazes. A ela igualmente se aplicam as críticas aqui feitas a estruturas do eixo cultural.

Estou chegando ao fim desta exposição. Quero externar os meus agradecimentos a todos pela atenção com que me ouviram, em especial àqueles que se dedicam ao nobre encargo de gerir instituições públicas. Devo dizer-lhes que as considerações aqui feitas são apenas pontos de vista, e não teses prontas e acabadas. Tudo o que foi dito originou-se do grande respeito conquistado pelos museus brasileiros e internacionais. Museus que, mundo afora, disseminam verdadeiras lições de cultura e civilização.

A preservação da história humana é algo essencial para a compreensão do mundo. Museus, exposições e arquivos, digitais ou em papel, eternizam acontecimentos. Aparentemente mais perceptível no universo das artes, a museologia tem igual relevância na difusão da ciência e da verdade. Museus ensinam, museus educam, museus civilizam. Museus contam, permanentemente, a fascinante narrativa do homem e suas possibilidades na arte, na ciência, e na justificação da vida.

Nota

1 Conferência do professor Jacques Marcovitch no seminário de abertura do II Simpósio Internacional de Pesquisa Museológica do Programa de Pós-Graduação Interunidades em Museologia da Universidade de São Paulo, realizado em 5 de outubro de 2015.

\section{Referências}

ASSIS, M. de. O velho Senado. In: . Obra completa. Rio de Janeiro: Nova Aguilar 1994. v.II.

BITTENCOURT, J. N. Para descongelar o futuro. Entre demandas do patrimônio, da modernidade, do poder, a luta pelo porvir dos museus. In: MAGALHÃES, A. M.; BEZERRA, R. Z. (Org.) Museus Nacionais e os desafios do Contemporâneo. Rio de Janeiro: Museu Histórico Nacional, 2011. p.106-35.

BOBBIO, N. et al. (Ed.) Dicionário de Política. Brasília: Editora da UnB, 1998. 
DE FARIA, M. L. Museus nacionais e desafios contemporâneos. Do museu revolucionário ao museu efêmero. In: MAGALHÃES, A. M.; BEZERRA, R. Z. (Org.) Museus Nacionais e os desafios do Contemporâneo. Rio de Janeiro: Museu Histórico Nacional, 2011 . p.62-75.

FIBICHER, B. Le succès d'un musée ne se mesure pas qu'aux chiffres de fréquentation. Le Temps, Suisse, 8 abr. 2015. Débats, p.8.

MARCOVITCH, J. Universidade em movimento. Revista USP, São Paulo, n.10, p.4350 , abril/maio/junho 2015.

MENESES, U. T. B. O museu tem futuro. Jornal do MARGS, n.58, jun. 2000. Disponível em: <http://www.margs.rs.gov.br/ndpa_sele_omuseutem.php>.

RESUMO - A preservação da história humana é algo essencial para a compreensão do mundo. Museus, exposições e arquivos, digitais ou em papel, eternizam acontecimentos. Por isso, sua necessária e ativa presença no futuro do Brasil depende de uma direção imbuída pela cultura de resultados e pautada na lógica museológica. Uma lógica que enfatiza a qualidade de serviços balizada em metas e métricas. Além de se debruçar sobre os modelos de governança, o texto analisa o museu como sistema, descreve o perfil esperado do seu dirigente e propõe uma visão prospectiva que norteia a construção do seu futuro.

PALAVRAS-CHAVE: Museologia, Governança, Qualidade, Desempenho, Museus.

ABSTRACT - The preservation of human history is essential to understanding the world. Museums, exhibitions and archives, both digital or on paper, eternalize events. Because of this, their active and necessary presence in the future of Brazil depends on a management imbued with a results-driven culture and guided by a museological logic that emphasizes quality of service, buoyed by metrics and goals. In addition to addressing models of governance, the text analyzes the museum as a system, describes the ideal profile of its management and proposes a prospective vision that will guide the construction of its future.

KEYWORDS: Museology, Governance, Quality, Performance, Museums.

Jacques Marcovitch é professor da Faculdade de Economia, Administração e Contabilidade (FEA) e do Instituto de Relações Internacionais (IRI) da Universidade de São Paulo. Foi diretor do Instituto de Estudos Avançados (1988-1993) e reitor (19972001) da Universidade de São Paulo. Publicou entre outras obras A universidade (im) possivel, Universidade viva e a USP em movimento. É membro do Conselho Deliberativo da Biblioteca Brasiliana José e Guita Mindlin e do Conselho Superior do Graduate Institute (IHEID), Genebra. @ - jmarcovi@usp.br

Recebido em 28.10.2015 e aceito em 18.11.2015.

${ }^{\text {I }}$ Faculdade de Economia, Administração e Contabilidade e Instituto de Relações Internacionais, Universidade de São Paulo. São Paulo/São Paulo, Brasil. 